\title{
Complete resolution of gastric amyloidosis after autologous stem cell transplantation
}

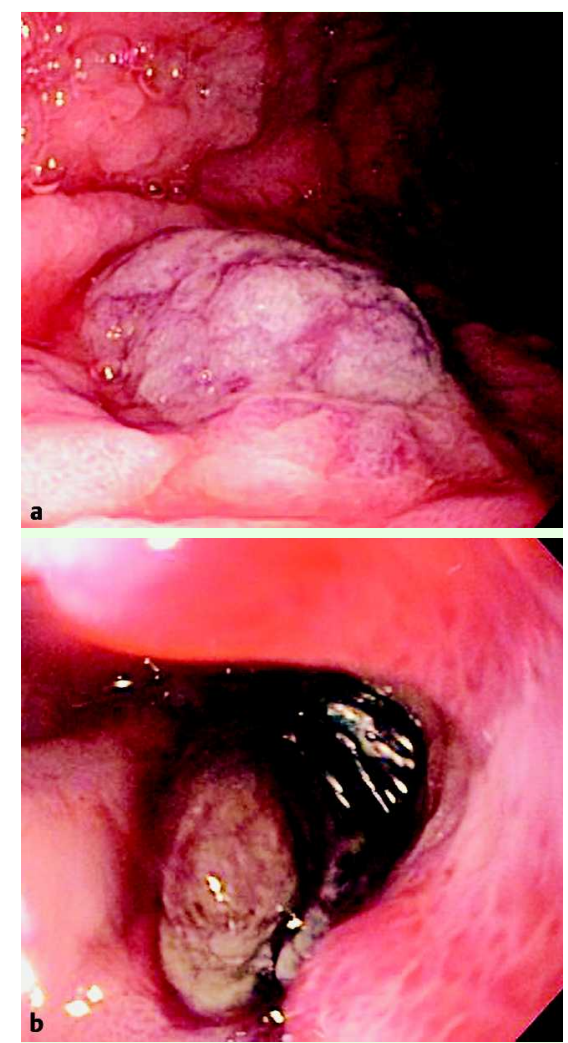

Fig. 1 Esophagogastroduodenoscopy findings. a A large pigmented lesion in the body of the stomach. b Giant ulcer in the cardia containing a large, necrotic, bleeding pigmented lesion.

A 48-year-old woman with multiple myeloma and amyloidosis presented with massive upper gastrointestinal bleeding 1 week after autologous stem cell transplantation (autologous-SCT). Esophagogastroduodenoscopy (EGD) demonstrated necrotic, purple, pigmented, friable lesions throughout the stomach ( $\bullet$ Fig. 1 a), along with a bleeding ulcer in the cardia containing a central pigmented lesion ( Fig. 1 b; Video 1) which was successfully treated with epinephrine $(1: 10000)$ injections. Biopsies demonstrated nodular amyloid deposition ( $\bullet$ Fig. 2) which was Congo-redpositive. The patient had no further hematemesis and was discharged home 4 days later. Ten months after autologousSCT, EGD revealed a normal stomach ( Fig. 3; Video 2) with no histologic evidence of amyloid.

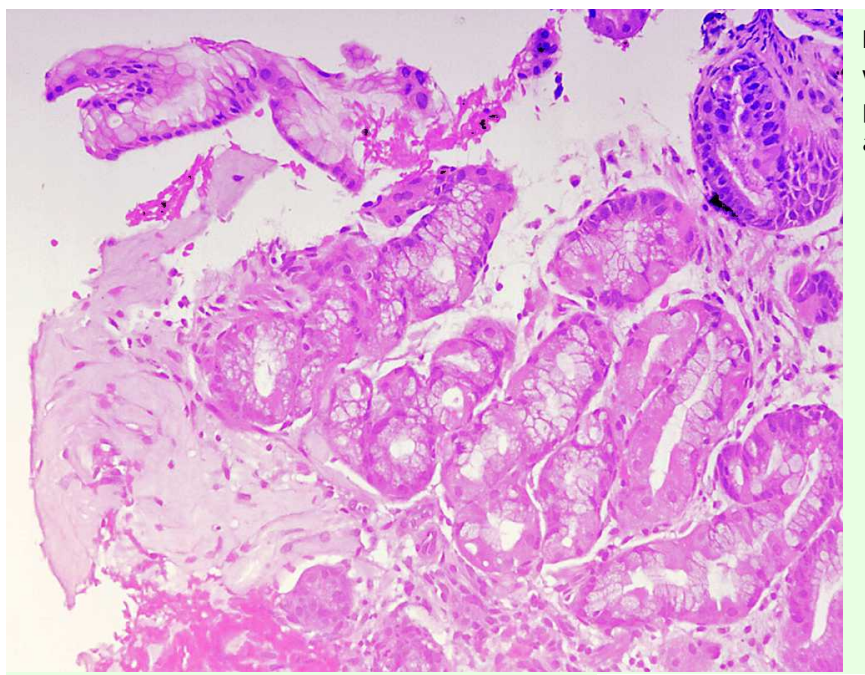

Fig. 2 Gastric biopsy with dense amyloid deposition in the mucosa at high magnification.

$\mathrm{AL}$ amyloid of the gastrointestinal tract involves the stomach in $8 \%$ of cases [1]. Only $1 \%$ of patients with gastric amyloidosis manifest symptoms such as bleeding $[1,2]$, which has been attributed to light-chain deposition in blood vessels causing increased friability and eventual bowel infarction [2,3]. Characteristic endoscopic findings include thickened folds, mucosal erosions, submucosal hematomas, ulcerations, and mucosal friability [2]. Histology demonstrates deposition of amorphous hyaline material on H\&E stain which is Congo-red-stain-positive. Treatment of AL amyloid is aimed at the underlying plasma cell disorder in order to decrease light-chain production. High-dose melphalan followed by autologous-SCT induces a complete hematologic response in the majority of patients in about 3 months [4,5]. This therapy may be associated with significant toxici-

\section{Video 1}

Large ulcer in the cardia containing a bleeding pigmented lesion. Numerous additional lesions are present throughout the stomach which, upon probing, are friable and necrotic.

\section{Video 2}

Complete resolution of gastric amyloid 10 months after autologous stem cell transplantation.

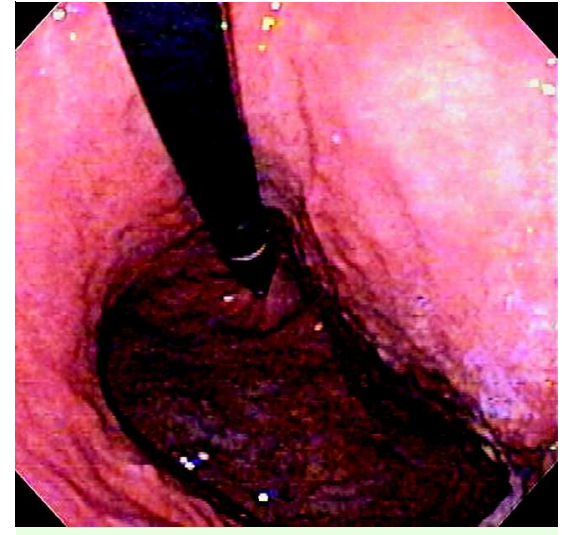

Fig. 3 Normal gastric cardia and fundus 2 months after autologous stem cell transplantation.

ty, especially in patients with underlying cardiac disease.

There are very limited published data documenting reversal of symptomatic gastrointestinal amyloid with multiple myeloma therapy $[4,5]$. We believe this is the first reported case of complete endoscopic and histologic resolution of gastrointestinal amyloid, particularly gastrointestinal amyloid causing bleeding, following autologous-SCT. In carefully selected patients with multiple myeloma, high-dose melphalan followed by autologous-SCT may be effective for symptomatic AL amyloid of the gastrointestinal tract.

Endoscopy_UCTN_Code_CCL_1AB_2AD_3AF 
D. Cherian ${ }^{1}$, K. Braun ${ }^{2}$, N. Flomenberg ${ }^{3}$, J. Palazzo ${ }^{4}$, D. Kastenberg ${ }^{2}$

Jefferson Medical College, Philadelphia, Pennsylvania, USA

2 Division of Gastroenterology and Hepatology, Thomas Jefferson University, Philadelphia, Pennsylvania, USA

3 Division of Medical Oncology, Thomas Jefferson University, Philadelphia, Pennsylvania, USA

${ }^{4}$ Division of Pathology, Thomas Jefferson University, Philadelphia, Pennsylvania, USA

\section{References}

1 Ebert EC, Nagar M. Gastrointestinal manifestations of amyloidosis. Am J Gastroenterol 2007; 102: 1 - 12

2 Chang HS, Myung SJ, Yang SK et al. Massive small bowel bleeding in a patient with amyloidosis. Gastrointest Endosc 2004; 59: $126-129$

3 Gilat T, Spiro HM. Amyloidosis and the gut. Dig Dis Sci 1968; 13: 619-633

4 Comenzo RL, Vosburgh E, Falk RH et al. Doseintensive melphalan with blood stem-cell support for the treatment of AL (amyloid light-chain) amyloidosis: survival and responses in 25 patients. Blood 1998; 91: $3662-3670$

5 Sanchorawala $V$, Wright $D G$, Seldin $D C$ et al. An overview of the use of high-dose melphalan with autologous stem cell transplantation for the treatment of AL amyloidosis. Bone Marrow Transplant 2001; 28 : 637-642
Bibliography

DOI 10.1055/s-2007-995793

Endoscopy 2008; 40: E167-E168

(c) Georg Thieme Verlag KG Stuttgart · New York . ISSN 0013-726X

Corresponding author

\section{Kastenberg, MD}

Division of Gastroenterology and Hepatology 132 South 10th Street

Philadelphia

PA 19107

USA

Fax: +1-215-5032578

David.Kastenberg@jefferson.edu 